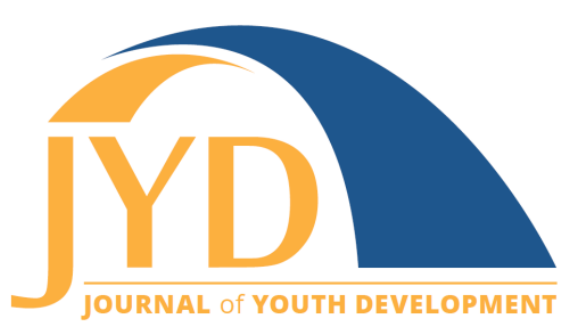

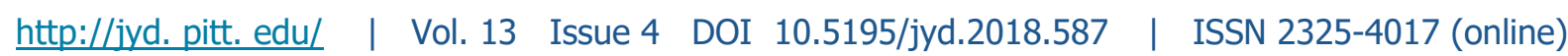

\title{
Developing Youth Competencies: The Impact of Program Quality
}

\author{
Tegan M. Smischney \\ University of Minnesota \\ smisc002@umn.edu \\ Matthew A. Roberts \\ University of Minnesota \\ robe0290@umn.edu \\ Kate Gliske \\ University of Minnesota \\ kgliske@umn.edu \\ Lynne M. Borden \\ University of Minnesota \\ Imborden@umn.edu

\section{Daniel F. Perkins} \\ Pennsy/vania State University \\ dfp102@psu.edu
}

\begin{abstract}
As youth programs have continued to evolve over the last 100 years, the field of program evaluation has advanced significantly in an effort to differentiate which youth program components are necessary to promote positive youth development (e.g., Eccles \& Gootman, 2002; Lerner et al., 2013). The Children, Youth, and Families at Risk (CYFAR) initiative funds a variety of sustainable community projects (SCPS) that aim to support at-risk youth and families and help them become healthy, positive, and contributing members of society (U.S. Department of Agriculture, n.d.). To ensure these programs are meeting CYFAR's goals, a required collection of common measures began in 2011 (University of Minnesota, 2017b). This study used CYFAR evaluation data to explore how specific program quality components (e.g. physical and psychological safety and relationship building) influence change in youth competencies. It
\end{abstract}

(c) $\mathrm{EY}_{\mathrm{EY}}$ New articles in this journal are licensed under a Creative Commons Attribution 4.0 License. This journal is published by the University Library System, University of Pittsburgh and is cosponsored by the University of Pittsburgh Press. The Journal of Youth Development is the official peer-reviewed publication of the National Association of Extension 4-H Agents and the National AfterSchool Association. 
Youth Competencies and Program Quality

was hypothesized that higher program quality ratings would be significantly associated with higher pretest to posttest change in youth competencies. Results indicated differential associations between the qualities of youth programs, particularly positive social norms and skill building, and changes in youth competencies. Implications for positive youth development programs are discussed.

Key words: program quality, positive youth development, youth competencies

\section{Introduction}

Over the last hundred years, youth programs have evolved from an emphasis on managing troubled youth to a more positive and proactive approach that envisions youth as developing individuals who can contribute to society (Perkins \& Borden, 2003; Roth \& Brooks-Gunn, 2016; Walker, Gambone, \& Walker, 2011). As a result, youth programs have focused primarily on promoting positive outcomes and reducing risk by providing enriching experiences that encourage positive emotional, social, behavioral, and cognitive development (Meschke, Peter, \& Bartholomae, 2012). A diverse array of positive youth development (PYD) programs often referred to as after-school or out-of-school programs have been created to meet these needs. Programs can be faith-based, recreational (e.g., football, baseball, swimming), or communitybased and vary widely in the activities they offer (e.g., socialization activities, homework help, community service, sports development) as well as in their goals and desired outcomes (Kremer, Maynard, Polanin, Vaughn, \& Sarteschi, 2015). There is evidence that participation in youth programs is associated with a variety of positive outcomes, including reduced delinquent behaviors and substance use (Agans et al., 2014; Anderson-Butcher \& Cash, 2010; Durlak, Weissberg, \& Pachan, 2010), increased academic achievement (Anderson-Butcher, Newsome, \& Ferrari, 2003; Durlak, Weissberg, et al., 2010), and positive social and emotional development (Durlak, Mahoney, Bohnert, \& Parente, 2010; Durlak, Weissberg, et al., 2010).

Youth development researchers (e.g., Eccles \& Gootman, 2002; Lerner et al., 2005; Lerner et al., 2013) have argued that the increases in positive outcomes following participation in highquality programs are driven by the development of characteristics known as the Five Cs: competence, confidence, character, connection, and caring. Competence concerns youth's ability to successfully navigate a variety of complex environments, including social (e.g., conflict management, communication), academic (e.g., attendance, grades), cognitive (e.g., decision making, planning), and vocational (e.g., work habits, career choice exploration) competence. Confidence is associated with having a positive sense of self-worth and self-efficacy. Connection involves building and strengthening positive bonds between youth and other people and institutions (e.g., school). Character is comprised of having respect for social norms and a 
Youth Competencies and Program Quality

strong sense of right and wrong. The final C, caring, involves a sense of empathy and sympathy for others' feelings and experiences. Promoting PYD and the Five Cs can reduce problem behaviors, such as substance use, depression, and delinquency (Jelicic, Bobek, Phelps, Lerner, \& Lerner, 2007) among youth and promote the development of a sixth C, contribution to community (Lerner, 2004; Perkins, Borden, Keith, Hoppe-Rooney, \& Villarruel, 2003).

Although PYD programs have the potential to make a positive impact and support the development of the Five Cs, not all programs do (Durlak, Weissberg, et al., 2010; Taheri \& Welsh, 2016). As a result, researchers, policymakers, and practitioners have increasingly recognized the importance of evaluating program quality to ensure that programs are meeting the needs of today's youth (Roth \& Brooks-Gunn, 2016; Yohalem \& Wilson-Ahlstrom, 2010). The field of program evaluation has advanced significantly over the last 40 years, progressing from narrative evaluations and participant satisfaction ratings to a more evidence-based approach focused on evaluating program outcomes utilizing rigorous experimental design (Arnold \& Cater, 2011). Although research suggests that high-quality programs are associated with positive youth outcomes, additional research is needed to understand the processes through which programs positively influence youth.

\section{Components of a Quality Youth Program}

A variety of features can influence how effective a youth program is at promoting healthy development in youth (Roth \& Brooks-Gunn, 2016). In 2002, the National Research Council released a comprehensive report regarding eight program features necessary for an effective youth program (Eccles \& Gootman, 2002; Perkins \& Borden, 2003). This list remains one of the most commonly cited in the literature (Roth \& Brooks-Gunn, 2016). The components include

- physical and psychological safety, a safe environment that is devoid of physical and psychological health dangers and promotes healthy and safe interactions among staff and peers;

- appropriate structure, age-appropriate supervision in a predictable and stable environment with clear rules, expectations, and boundaries;

- supportive relationships, positive relationships with non-familial caring adults that are trustworthy and caring, provide a sense of connection, and demonstrate open and positive communication;

- opportunities for belonging, a sense of fitting in or being included in something meaningful regardless of sexual orientation, race/ethnicity, gender, or disability status; 
Youth Competencies and Program Quality

- positive social norms, formal and informal behavioral expectations that reinforce prosocial behaviors (e.g., safe sexual behaviors, refraining from substance use) while taking into consideration individual and cultural differences;

- support for efficacy and mattering, youth-based activities that challenge and empower youth by increasing responsibility and promoting autonomy in a way that allows youth to make a meaningful difference in their community;

- opportunities for skill building, learning experiences that support youth as they build their emotional, intellectual, physical, psychological, and social skill sets; and

- integration of family, school, and community efforts, collaboration among families, schools, and community organizations to maximize resources and increase the likelihood of a child getting the appropriate support they need to succeed (Eccles \& Gootman, 2002).

Eccles and Gootman (2002) argued that programs that have these eight components will be better at supporting positive and healthy development in youth. Consequently, evaluation research continues to use these components as a benchmark for assessing effective youth programs (Deutsch, Blyth, Kelley, Tolan, \& Lerner, 2017). One federal program that has sought to support high quality youth development programs is the Children, Youth, and Families at Risk (CYFAR) initiative. A selection of the programs supported by CYFAR is the focus of the current study.

\section{The Children, Youth, and Families at Risk (CYFAR) Initiative}

In 1991, the Department of Agriculture Cooperative State Research, Education and Extension Service began an effort to support positive developmental outcomes through community-based programming for at-risk children, youth, and families. The CYFAR initiative has since funded sustainable community projects (SCPs) in over 600 communities across the United States and territories, in an effort to promote resilience and help youth gain the knowledge and skills necessary to live successful, healthy, and contributing lives (U.S. Department of Agriculture, n.d.). All projects share a common strategic objective to support community educational programs for at-risk children, youth, and families that are grounded in research and based on locally identified needs (U.S. Department of Agriculture, University of Minnesota, \& Penn State, 2016).

Years of research have established that high-quality youth programs promote the development of a variety of positive effects, including prosocial relational skills with peers and adults, 


\section{Youth Competencies and Program Quality}

academic achievement, healthy living, and community involvement (e.g., Kataoka \& Vandell, 2013; Leos-Urbel, 2013; Smith, Witherspoon, \& Wayne Osgood, 2017; Zarrett \& Bell, 2014). However, very little is known about the specific processes governing the relationship between youth programming and positive outcomes (Roth \& Brooks-Gunn, 2016). For example, while positive adult-youth relationships have long been considered to be the cornerstone of successful youth programs (e.g., Rhodes, 2004), few researchers have empirically tested the association between supportive relationships and positive youth outcomes (Roth \& BrooksGunn, 2016). Youth programs often have finite resources, therefore information about which components to emphasize during development and staff training in order to achieve the youth competencies most central to their stated mission is critical. The present study sought to explore how specific program quality components (e.g., physical and psychological safety and supportive relationships) influenced change in youth competencies (e.g., personal values, critical thinking) following participation in a range of youth programs. Because this study represents one of the first attempts at investigating the connection between program quality and youth outcomes, it was hypothesized that youth program quality would be positively associated with change in youth competencies.

\section{Methods}

The current study uses a portion of the data collected through the CYFAR initiative. To ensure that SCPs were meeting CYFAR's goals, a pilot program designed to provide support for evaluation of the SCPs was started in 2010 and all CYFAR SCPs funded beginning in 2011 were required to collect CYFAR Common Measure data (University of Minnesota, 2017b). The CYFAR common measures data relate to demographics, participation level, program quality, and the core competencies. The core competency instrument measures youth's attitudes and behaviors as they relate to the five common competencies of all CYFAR programs including caring, social conscience, personal values, decision making, and critical thinking (University of Minnesota, 2017a). The core competencies encompass many of the characteristics of the Five Cs of PYD. The CYFAR evaluation design includes collection of the common measures when each youth begins a project (pretest) and when the project ends (posttest). Data were collected from CYFAR SCPs submitting data between 2011 and September of 2017. Each SCP was individually required to obtain Institutional Review Board (IRB) approval, as well as assent and consent from the youth participants and their guardian. 
Journal of Youth Development | http://jyd.pitt.edu/ | Vol. 13 Issue 4 DOI 10.5195/jyd.2018.587

Youth Competencies and Program Quality

\section{Participants}

Table 1. CYFAR Participant Demographics at Pretest

\begin{tabular}{|c|c|c|c|}
\hline Characteristic & $n$ & $\%$ & \%adj.* \\
\hline \multicolumn{4}{|l|}{ Gender } \\
\hline Male & 173 & $32.7 \%$ & $40.6 \%$ \\
\hline Female & 253 & $47.8 \%$ & $59.4 \%$ \\
\hline Missing & 103 & $19.5 \%$ & \\
\hline \multicolumn{4}{|l|}{ Grade } \\
\hline $3^{\text {rd }}-5^{\text {th }}$ & 73 & $13.8 \%$ & $15.2 \%$ \\
\hline $6^{\text {th }}-8^{\text {th }}$ & 279 & $52.7 \%$ & $58.1 \%$ \\
\hline $9^{\text {th }}-12^{\text {th }}$ & 120 & $22.7 \%$ & $25.0 \%$ \\
\hline Post-HS & 8 & $1.5 \%$ & $1.6 \%$ \\
\hline Missing & 49 & $9.3 \%$ & \\
\hline \multicolumn{4}{|l|}{ Ethnicity } \\
\hline Hispanic or Latino & 67 & $12.7 \%$ & $17.3 \%$ \\
\hline Not Hispanic or Not Latino & 320 & $60.5 \%$ & $82.7 \%$ \\
\hline Missing & 142 & $26.8 \%$ & \\
\hline \multicolumn{4}{|l|}{ Race } \\
\hline White & 204 & $38.6 \%$ & $56.7 \%$ \\
\hline Black & 103 & $19.5 \%$ & $28.6 \%$ \\
\hline Native American & 20 & $1.7 \%$ & $5.6 \%$ \\
\hline Asian & 4 & $0.8 \%$ & $1.1 \%$ \\
\hline Native Hawaiian/Pacific Islander & 4 & $0.8 \%$ & $1.1 \%$ \\
\hline Multiple races & 25 & $4.7 \%$ & $7.2 \%$ \\
\hline Missing & 169 & $31.9 \%$ & \\
\hline
\end{tabular}

*Indicates the percent with missing excluded

Participants were 529 at-risk youth who participated in 18 SCPs across 19 different states during the study period. The SCPs represented in this study varied based on a number of characteristics (see Table 1 for full demographic information). While the majority of participants were in middle school or high school, a portion of participants were elementary-aged youth. Each program engaged youth over the course of a school-year or in multi-year initiatives, often meeting twice a month or more during that time. While all programs sought to increase positive outcomes in children, content varied across programs as well as within programs across states. 


\section{Youth Competencies and Program Quality}

For example, many of the SCPs were based on 4-H curriculum; however, 4-H Purdue Athletic Life Success (PALS) in Indiana focused on encouraging youth in third through sixth grades to remain active and healthy year-round by engaging in weekly activities as well as a 4-week day camp during the summer. In contrast, 4-H Science, Technology, and Math (STEM) Education \& Science Literacy in North and South Carolina engaged youth 5 to 12 years old in STEM afterschool programs in an effort to increase youth interest in STEM-related careers (U.S. Department of Agriculture et al., 2016).

De-identified data from only those youth with a matching pre-program and post-program survey were used. Data collection was managed by each SCP conducting the programming; therefore, not all measures were administered consistently. As a result, a large percentage of the youth demographic data was missing. Race and ethnicity were most frequently missing, but all demographic characteristics included portions that were missing. Most of the youth reported they were either at a middle school or high school grade level.

\section{Measures}

\section{Program Quality Scales}

The quality of the youth programs was assessed at the post-program survey time point using a 22-item Youth Program Quality Instrument developed by Borden, Wiggs, Schaller, \& Schlomer (2012), from Borden and Perkins (2003). This instrument assesses five of the eight program quality components identified by Eccles \& Gootman (2002). All items were rated using a 5-point Likert scale from "Never" to "Always." Composite scores were computed using the average of all items for the Physical and Psychological Safety $(M=3.60, S D=0.83)$, Supportive Relationships $(M=4.13, S D=0.77)$, Positive Social Norms $(M=3.73, S D=0.88)$, Support for Efficacy and Mattering ( $M=3.50, S D=0.97)$, and Opportunities for Skill Building $(M=3.72, S D=0.85)$ scales. Reliability was calculated for all scales; the reliability estimates for all scales were acceptable (Cronbach's Alpha ranged from .74 to .88). A short description of the scale items follows.

\section{Physical and Psychological Safety}

This scale has six items, four of which are reverse-scaled. Example items include, "Young people say mean things to others or call them names," (reverse scaled) and "If someone is being picked on, young people try to stop it." 
Youth Competencies and Program Quality

\section{Supportive Relationships}

This scale has three items. The items are, "Adults make sure rules are being followed," "Adults are eager to help young people," and "Young people are willing to help each other."

\section{Positive Social Norms}

The positive social norms scale has four items. Example items include "Young people respect one another" and "Adults treat young people fairly."

\section{Support for Efficacy and Mattering}

This scale has three items. The items are: "Young people and adults work together to plan activities," "Young people choose the things they want to do," and "Young people are encouraged to be leaders."

\section{Opportunities for Skill Building}

This scale has six items. Example items include: "Young people learn from activities that are challenging" and "Young people learn to treat others with respect."

\section{Core Competency Measures}

In addition to the program quality instrument, youth were asked to complete five core competency scales measuring social conscience, personal values, caring, critical thinking, and decision making. All items were rated on 4-point Likert-type scales in which a higher score indicated greater competency. Composite scores were calculated for all core competency scales by summing all items in each scale. Change scores were then calculated by subtracting the composite score on the pre-program survey from the corresponding composite score on the post-program survey for the Social Conscience $(M=0.23, S D=3.36)$, Personal Values ( $M=$ $0.00, S D=2.86)$, Caring $(M=-0.02, S D=5.07)$, Critical Thinking $(M=-0.09, S D=3.35)$, and Decision Making $(M=-0.13, S D=3.35)$ scales. Change scores did not significantly differ across demographic groups for any of the five core competencies.

Reliability was calculated and estimates were acceptable for all scales. Cronbach's Alpha ranged from .79 to .86 for pretest scales and .78 to .92 for posttest scales. A description of the scale items follows. 


\section{Social Conscience}

The Social Conscience scale includes six items from Lerner's Social Conscience scale; a subscale of the Character scale (Lerner, 2008b). Respondents indicate the importance of each item in their life on a scale ranging from "Not Important" to "Extremely Important." Examples of items are: "Helping other people" and "Helping to make sure all people are treated fairly."

\section{Personal Values}

The Personal Values scale includes five items from Lerner's Personal Values scale; a subscale of the Character scale (Lerner, 2008a). Respondents also answer these items by indicating the importance of each in their life on a scale ranging from "Not Important" to "Extremely Important." Examples of items include: "Telling the truth, even when it's not easy" and "Doing what I believe is right, even if my friends make fun of me."

\section{Caring}

The Caring scale includes nine items from Lerner's Caring scale (Lerner, 2008). Respondents indicate how well a statement describes themselves on a scale ranging from "Not Well" to "Very Well." Examples of items include: "When I see someone being picked on, I feel sorry for them" and "It makes me sad to see a person who doesn't have friends."

\section{Critical Thinking}

The Critical Thinking scale was developed from Mincemoyer and Perkins' scale Critical Thinking in Everyday Life (2001) and adapted by Cater et al. (2010a). The response options ranged from "Never" to "Always." Youth are prompted to respond to the items in the context of the following statement: "When I think about things I . . . " Example items include: "Can easily express my thoughts on a problem" and "Compare ideas when thinking about a topic."

\section{Decision Making}

The Decision-Making scale was developed from Mincemoyer and Perkins' scale Making Decisions in Everyday Life (2001) and adapted by Cater et al. (2010b). The response options ranged from "Never" to "Always." Youth were asked to answer items in the context of the following statement: "When I have a decision to make I . . . " Example items include: "Look for information to help me understand the problem." and "Think of past choices when making new decisions." 


\section{Youth Competencies and Program Quality}

\section{Results}

The results are reported in two sections. First, the relationship between program quality and the change in core competency scores are presented; then, regression models are described.

\section{The Relationship Between Program Quality and Core Competencies}

Pearson $r$ correlations were calculated to determine the relationship between youth ratings of program quality and change in core competency scale scores from pre- to post-program test. Pairwise deletion of missing data was used to assure the results were inclusive of as many youth and projects as possible. Of the five core competency scales, between $3.4 \%$ and $11 \%$ of youth were missing at least one scale, while $2.1 \%$ to $23.3 \%$ of youth were missing at least one program quality scale. A consistent pattern of significant but weak relationships was found among many of the program quality scales and the social conscience, personal values, critical thinking and decision-making core competencies (see Table 2). However, no relationship was found between program quality and the caring scale.

\section{Table 2. Correlations Between Program Quality Scales and Change in Core Competency Change Scores}

\begin{tabular}{|l|c|c|c|c|c|}
\hline & \multicolumn{5}{|c|}{ Change in Core Competency } \\
\hline Program quality scale & Social & Personal & Caring & Critical & Decision \\
thinking & making \\
\hline Physical and psychological safety & $.09 *$ & .07 & .01 & .05 & .06 \\
\hline Supportive relationships & $.15^{*}$ & $.15^{* *}$ & .06 & $.12^{*}$ & .09 \\
\hline Positive social norms & $.16^{* *}$ & $.17^{* *}$ & .09 & $.18^{* *}$ & $.14^{* *}$ \\
\hline Support for efficacy and mattering & $.14 * *$ & .09 & .02 & $.13^{*}$ & $.11^{*}$ \\
\hline Opportunities for skill building & $.23 * *$ & $.20 * *$ & .07 & $.14^{* *}$ & $.12^{* *}$ \\
\hline
\end{tabular}

Note. Pairwise deletion of missing data was used in calculating the correlation coefficients. Consequently, sample sizes varied between scales ( $N$ s ranged from 359 to 501 ). $* p<.05, * * p<.01$

\section{Program Quality and Core Competency Change Models}

Next, in order to examine which aspects of program quality might have the greatest impact on youth competencies, regression models were explored. Two programs were excluded from analyses due to missing entire program quality scales. One reason for the missing scales was due to some SCPs IRBs refusing to allow youth to answer questions about program staff. Youth 
Youth Competencies and Program Quality

from programs included in analysis did not differ significantly than those in the excluded programs on any of the measures of change in core competencies. However, there were significant differences between the two groups on the supportive relationships, positive social norms, and physical and psychological safety scales, with the youth from the two excluded programs scoring lower on average. Because no relationship was found between the Program Quality scales and the Caring scale, regression models were only conducted for the other four core competency scales. A backward elimination multiple linear regression model was used, removing predictors in a step-wise fashion in order to maximize the adjusted $R^{2}$ in order to explore the potential impact individual program quality scales have in predicting change in personal values, social conscience, critical thinking, and decision making. A concern with this analysis was the potential for multicollinearity among the program quality scales, this concern was furthered by finding moderate to strong, significant correlations between the five program quality scales (ranging from .33 to .70). However, all VIF (variance inflation factor) and tolerance values were within acceptable limits (below 5 and above .1 respectively); therefore, analysis of the models continued. See Table 3 for full regression coefficients.

\section{Social Conscience}

Stepwise regression analysis was used to test if the five aspects of program quality significantly predicted change in participants' social conscience. The full model including all program quality scales explained $8.5 \%$ of the variance and was a significant predictor of change in social conscience $\left(R^{2}\right.$ adj. $\left.=.09, f(5,361)=7.81, p<.001\right)$. Skill Building was the only scale that contributed significantly to the full model. Using .10 as criteria for elimination, all scales except Skill Building were removed from the final model. This did not result in a significant change in the final model's ability to predict social conscience $\left(R^{2}\right.$ adj. $\left.=.08, f(1,365)=34.13, p<.001\right)$.

\section{Personal Values}

Stepwise regression analysis was used to test if the five aspects of program quality significantly predicted change in participants' personal values. The full model including all program quality scales explained $5 \%$ of the variance and was a significant predictor of change in personal values $\left(R^{2}\right.$ adj. $\left.=.05, F(5,356)=4.76, p<.001\right)$. Only Physical and Psychological Safety and Skill Building contributed significantly to the full model. In the final model, Support for Efficacy and Mattering and Supportive Relationships were removed without resulting in a significant change in the model's ability to predict change in personal values $\left(R^{2}\right.$ adj. $=.05, F(3,358)=$ $7.82, p<.001)$. Physical and Psychological Safety, Positive Social Norms, and Skill Building all contributed significantly to the final model. 


\section{Decision Making}

Stepwise regression analysis was used to test if the five aspects of program quality significantly predicted change in participants' decision making. The full model including all program quality scales explained $4.5 \%$ of the variance and was a significant predictor of change in decision making $\left(R^{2}\right.$ adj. $\left.=.05, f(5,328)=4.12, p<.001\right)$. Only Positive Social contributed significantly to the full model. The final model eliminated Supportive Relationships, Support for Efficacy and Mattering, and Skill Building without causing a significant change in the model's ability to predict change in decision making $\left(R^{2}\right.$ adj. $\left.=.05, f(2,331)=10.04, p<.001\right)$. Only Positive Social Norms contributed significantly to the final model, while Physical and Psychological Safety did not.

\section{Critical Thinking}

Stepwise regression analysis was used to test if the five aspects of program quality significantly predicted change in participants' critical thinking. The full model including all program quality scales explained $1.8 \%$ of the variance and was a significant predictor of change in critical thinking $\left(R^{2}\right.$ adj. $\left.=.02, f(5,329)=2.25, p<.05\right)$. None of the variables in the full model contributed significantly to the model. The final model included only Positive Social Norms and did not significantly differ from the model's ability to predict change in critical thinking ( $R^{2}$ adj. $=$ $.03, f(1,333)=9.53, p<.01)$. 
Journal of Youth Development ｜ http://jyd.pitt.edu/ | Vol. 13 Issue 4 DOI 10.5195/jyd.2018.587

Youth Competencies and Program Quality

Table 3. Backward-Elimination Multiple Linear Regression Full and Final Models With Four Core Competencies as Dependent Variables

\begin{tabular}{|c|c|c|c|c|c|c|c|c|}
\hline & \multicolumn{4}{|c|}{ Full Model } & \multicolumn{4}{|c|}{ Final Model } \\
\hline & B & $S E$ & $\boldsymbol{\beta}$ & $\begin{array}{c}\text { Model } \\
\text { adjusted } \\
R^{2}\end{array}$ & B & SE & $\beta$ & $\begin{array}{c}\text { Model } \\
\text { adjusted } \\
\boldsymbol{R}^{2}\end{array}$ \\
\hline Change in social conscience & & & & $8.5 \%$ & & & & $8.3 \%$ \\
\hline Physical and psychological safety & -.49 & .27 & -.12 & & & & & \\
\hline Supportive relationships & -.08 & .35 & -.02 & & & & & \\
\hline Positive social norms & .46 & .33 & .12 & & & & & \\
\hline Support for efficacy and mattering & -.24 & .24 & -.07 & & & & $\mathrm{f}$ & \\
\hline Opportunities for skill building & 1.23 & .31 & $.32 * * *$ & & 1.13 & .19 & $.29 * * *$ & \\
\hline Change in personal values & & & & $5.0 \%$ & & & & $5.4 \%$ \\
\hline Physical and psychological safety & -.56 & .24 & $-.16 *$ & & -.56 & .24 & $-.16^{*}$ & \\
\hline Supportive relationships & .04 & .30 & .01 & & & & & \\
\hline Positive social norms & .54 & .29 & .17 & & .54 & .27 & $.17^{*}$ & \\
\hline Support for efficacy and mattering & -.14 & .21 & -.05 & & & & & \\
\hline Opportunities for skill building & .62 & .27 & $.19 *$ & & .54 & .22 & $.17^{*}$ & \\
\hline Change in decision making & & & & $4.5 \%$ & & & & $5.1 \%$ \\
\hline Physical and psychological safety & -.53 & .30 & -.12 & & -.54 & .30 & -.12 & \\
\hline Supportive relationships & -.16 & .40 & -.03 & & & & & \\
\hline Positive social norms & 1.12 & .36 & $.29 * *$ & & 1.16 & .27 & $.30 * * *$ & \\
\hline Support for efficacy and mattering & .15 & .26 & .04 & & & & & \\
\hline Opportunities for skill building & .08 & .34 & .02 & & & & & \\
\hline Change in critical thinking & & & & $1.8 \%$ & & & & $2.5 \%$ \\
\hline Physical and psychological safety & -.11 & .31 & -.03 & & & & & \\
\hline Supportive relationships & -.29 & .40 & -.06 & & & & & \\
\hline Positive social norms & .65 & .37 & .16 & & .66 & .21 & $.17 * *$ & \\
\hline Support for efficacy and mattering & .02 & .27 & .01 & & & & & \\
\hline Opportunities for skill building & .36 & .35 & .09 & & & & & \\
\hline
\end{tabular}

Note. $* p<.05, * * p<.01, * * * p<.001$ 


\section{Discussion}

This study represents one of the first investigations in the literature into the connection between program quality and outcomes. Its main goal was to explore how program quality components, specifically, physical and psychological safety, supportive relationship, positive social norms, support for efficacy and mattering, and opportunities for skill building influenced a change in youth competencies related to social conscience, caring, personal values, critical thinking, and decision making following participation in a youth program. It was hypothesized that participants who rated program quality higher would also have higher pretest to posttest change scores. Results indicated differential associations between the varying qualities of youth programs and changes in youth competencies. Two primary findings emerged: first, higher youth ratings of programs' skill building were associated with greater change in youth's social conscience and personal values and second, higher youth ratings of programs' positive social norms were associated with greater change in youth's personal values, decision making, and critical thinking. Furthermore, higher youth ratings of physical and psychological safety were associated with less change in youth's personal values, while supportive relationships and support for efficacy and mattering were not significantly associated with any youth competency outcomes. The lack of a significant relationship between any of the core competencies and supportive relationships was initially surprising; however, in their review of positive youth-staff relationships in after-school settings, Rhodes (2004) suggests that the quality of these relationships may affect youth outcomes both directly, through the close bonds shared with youth program staff, and indirectly, through the development of a warm and supportive program atmosphere. The findings from the present study suggest the direct effect of supportive relationships on youth outcomes may not be as significant as initially thought.

Instead, the two aspects of program quality that were most implicated in a change in youth self-reported competencies were positive social norms and skill building. Previous research has shown that youth programs promote positive social norms by communicating clear expectations for positive behavior that are consistent with the group's norms (Cheng, Siu, \& Leung, 2006). The findings from the current study suggest that perhaps there is a cognitive toll to being in an environment where respect for others isn't emphasized and behavioral expectations are not upheld that interferes with youth's ability to think critically and make good decisions. Skill building has previously been shown to be promoted in programs that offer youth the opportunity to develop physical, academic, social, and emotional skills that benefit them both now and in the future (Dawes \& Larson, 2011). Perhaps increasing youth's skills increases their 
Youth Competencies and Program Quality

self-confidence and sense of competence, emboldening them to stand up for what they believe in, to be more truthful, and to give back to those around them.

These results, while preliminary, have several implications for youth programming. First, evidence of differential effectiveness of program quality components on each core competency suggests that program developers should decide early on which youth outcomes are of greatest priority in order to ensure these quality components are emphasized amidst finite resources (e.g., money, youth program staff time). Second, supportive relationships within the context of youth programs may operate differently than previously shown. An earlier meta-analysis found that youth who reported higher levels of relationship quality with youth program staff displayed more positive developmental outcomes across multiple domains than those with lower quality relationships (DuBois, Holloway, Valentine, \& Cooper, 2002). However, this study suggests that supportive relationships may not be the driving feature of change in youth outcomes. Instead, it is possible that positive relationships between youth and program staff may be an important element indirectly embedded within other quality components. For example, youth who value their relationship with program staff may be more likely to internalize and follow the communicated rules of the group than those who don't value maintaining a relationship with their leaders. Third, the inverse relationship between the quality component physical and psychological safety and change in personal values was unexpected, and warrants further exploration in future studies. Finally, these results suggest that program quality should be considered and studied according to its components rather than as a single, unitary construct, which allows for a more nuanced understanding of the functional elements involved in developing high quality youth programming.

\section{Limitations and Future Directions}

While this study represents an important preliminary investigation into the relationship between program quality and change in youth competencies, there are several important limitations to take into consideration when interpreting the findings. First, the variation in programming offered by each SCP may have affected the findings. This study used the full sample of youth with a matching pre- and post-program survey who completed the program quality and core competency scales in order to maximize the number of programs included, thereby offering more complete evidence of the effect of a national initiative on individual program outcomes. Consequently, the sample included programs with a very diverse mixture of programming and a wide scope of goals and areas of focus. Among the potential programming areas of focus in CYFAR SCPs are nutrition, science, technology, and workforce preparation. A single SCP may 
Youth Competencies and Program Quality

have multiple areas of focus. Indeed, everything from program duration and frequency to population and environment varies between SCPs. The impact of program quality on the core competencies may vary with the programming offered. For example, an SCP with a science focus might provide programming that is more likely to improve a youth's critical thinking and decision-making skills as opposed to the other core competency areas; this could make the connection between program quality and critical thinking or decision-making outcomes more potent for SCPs offering this focus of programming. Future studies should endeavor to test the relationship between program quality and youth competencies using the program as a level of analysis. This will allow for a comparison of quality among programs and may provide additional information about the relationship between program quality and youth competencies.

Second, without the use of a control group, it is impossible to know whether changes between pretests and posttests can be attributed solely to program participation. Future studies should include the use of non-treatment controls in order to allow for a controlled test of the effect of program quality on youth outcomes. Third, there was a significant amount of missing data, ranging from $2 \%$ to $23 \%$ of the total sample depending on the scale used. Because data collection was done remotely and managed by each SCP, it was extremely difficult to ensure data were being collected accurately. While this led to putting procedures in place to ensure more accurate data collection going forward, it impacted the results from the current study. Missing data were deleted from analyses in a pair-wise manner in order to be inclusive of as much youth data as could reasonably be included, but this likely resulted in an increase in measurement error, ultimately influencing the validity of the results. Missing demographic characteristics had the added limitation of decreasing our understanding of the sample characteristics and limiting follow-up analyses. Finally, little information could be gleaned from the initial measures of program participation and dosage, which limited our ability to draw conclusions about the amount of time youth spent in programming. Both of these measures have been improved for the next phase of data collection, ensuring future studies of CYFAR SCPs will involve a more nuanced investigation of youth's participation in programming.

This study provides preliminary evidence for differential effects among varying features of youth programs' quality and changes in youth competencies. While this study represents a novel investigation of youth programming at a national level, the considerable threats to the validity means the findings should be interpreted with caution. Given the amount of missing data and diversity in programs included, it is possible that the estimates derived from the regressions are weaker than would be found otherwise. As a result, other youth program researchers should consider using these preliminary findings as a starting point when considering how the various 


\section{Youth Competencies and Program Quality}

components of program quality ultimately affect youth outcomes. Determining if some program quality components really do play a stronger role in developing youth competencies may help inform youth programs on where to focus effort and resources. While great progress has been made in recent years by emphasizing the importance of quality programming for youth, more evidence is needed. With limited funding available to support programming, it is critical that the field gain a better understanding of how different aspects of youth programs positively impact youth participants so the next generation of programs can maximize the benefits imparted to the youth they serve.

\section{References}

Agans, J. P., Champine, R. B., DeSouza, L. M., Mueller, M. K., Johnson, S. K., \& Lerner, R. M. (2014). Activity involvement as an ecological asset: Profiles of participation and youth outcomes. Journal of Youth and Adolescence, 43(6), 919-932. doi:10.1007/s10964-014-0091-1

Anderson-Butcher, D., \& Cash, S. J. (2010). Participation in boys and girls clubs, vulnerability, and problem behaviors. Children and Youth Services Review, 32(5), 672-678. doi:10.1016/J.CHILDYOUTH.2010.01.002

Anderson-Butcher, D., Newsome, S. W., \& Ferrari, T. M. (2003). Participation in boys and girls clubs and relationships to youth outcomes. Journal of Community Psychology, 31(1), 39-55. doi:10.1002/jcop.10036

Arnold, M. E., \& Cater, M. (2011). From then to now: Emerging directions for youth program evaluation. Journal of Youth Development, 6(3), 82-94. doi:10.5195/jyd.2011.176

Borden, L. M., \& Perkins, D. F. (2003). Youth program quality instrument [Measurement instrument]. Unpublished instrument.

Borden, L. M., Wiggs, C. B., Schaller, A., \& Schlomer, G. L. (2012). Engaging youth in evaluation: Using clickers for data collection. Journal of Youth Development, 71 , 147-151. doi:10.5195/JYD.2012.159

Cater, M., Arnold, M., Bouillion Diaz, L., Heck, K., Mead, J., Spears, B., . . LeMenestrel, S. (2010a). Scale: Critical thinking [Measurement instrument]. Washington, D.C.

Cater, M., Arnold, M., Bouillion Diaz, L., Heck, K., Mead, J., Spears, B., . . LeMenestrel, S. (2010b). Scale: Decision making [Measurement instrument]. Washington, D.C.

Cheng, H. C. H., Siu, A. M. H., \& Leung, M. C. M. (2006). Prosocial involvement as a positive youth development construct: Conceptual bases and implications for curriculum development. International Journal of Adolescent Medical Health, 18(3), 393-400. doi:10.1515/IJAMH.2006.18.3.393 
Journal of Youth Development | http://jyd.pitt.edu/ | Vol. 13 Issue 4 DOI 10.5195/jyd.2018.587

\section{Youth Competencies and Program Quality}

Dawes, N. P., \& Larson, R. (2011). How youth get engaged: Grounded-theory research on motivational development in organized youth programs. Developmental Psychology, 4Х1), 259-269. doi:10.1037/a0020729

Deutsch, N. L., Blyth, D. A., Kelley, J., Tolan, P. H., \& Lerner, R. M. (2017). Let's talk after-school: The promises and challenges of positive youth development for after-school research, policy, and practice. In N. Deutsch (Ed.), After-school programs to promote positive youth development (pp. 45-68). Cham, Switzerland: Springer.

DuBois, D. L., Holloway, B. E., Valentine, J. C., \& Cooper, H. (2002). Effectiveness of mentoring programs for youth: A meta analytic review. American Journal of Community Psychology, 30(2), 157-197. doi:10.1023/A:1014628810714

Durlak, J. A., Mahoney, J. L., Bohnert, A. M., \& Parente, M. E. (2010). Developing and improving afterschool programs to enhance youth's personal growth and adjustment: A special issue of AJCP. American Journal of Community Psychology, 45(3-4), 285-293. doi:10.1007/s10464-010-9298-9

Durlak, J. A., Weissberg, R. P., \& Pachan, M. (2010). A meta-analysis of after-school programs that seek to promote personal and social skills in children and adolescents. American Journal of Community Psychology, 45(3-4), 294-309. doi:10.1007/s10464-010-9300-6

Eccles, J. S., \& Gootman, J. A. (2002). Features of positive developmental settings. In Community programs to promote youth development (pp. 86-118). Washington, DC: National Academy Press.

Jelicic, H., Bobek, D. L., Phelps, E., Lerner, R. M., \& Lerner, J. V. (2007). Using positive youth development to predict contribution and risk behaviors in early adolescence: Findings from the first two waves of the 4-H Study of positive youth development. International Journal of Behavioral Development, 31(3), 263-273. doi:10.1177/0165025407076439

Kataoka, S., \& Vandell, D. L. (2013). Quality of afterschool activities and relative change in adolescent functioning over two years. Applied Developmental Science, 173), 123-134. doi:10.1080/10888691.2013.804375

Kremer, K. P., Maynard, B. R., Polanin, J. R., Vaughn, M. G., \& Sarteschi, C. M. (2015). Effects of afterschool programs with at-risk youth on attendance and externalizing behaviors: A systematic review and meta-analysis. Journal of Youth and Adolescence, 44(3), 616-636. doi:10.1007/s10964-014-0226-4

Leos-Urbel, J. (2013). What works after school? The relationship between after-school program quality, program attendance, and academic outcomes. Youth \& Society, 4オ5), 684-706. doi:10.1177/0044118X13513478

Lerner, R. M. (2004). Liberty: Thriving and civic engagement among America's youth. Thousand Oaks, CA: Sage. 
Journal of Youth Development | http://jyd.pitt.edu/ | Vol. 13 Issue 4 DOI 10.5195/jyd.2018.587

Youth Competencies and Program Quality

Lerner, R. M. (2008a). Personal values [Measurement instrument]. Retrieved from https://cyfar.org/sites/default/files/PsychometricsFiles/Personal Values \%28middle school\%29.pdf

Lerner, R. M. (2008b). Social conscience [Measurement instrument]. Retrieved from https://cyfar.org/sites/default/files/PsychometricsFiles/Social Conscience \%28middle school\%29_1_0.pdf

Lerner, R. M., Lerner, J. V., Almerigi, J. B., Theokas, C., Phelps, E., Gestsdottir, S., ... von Eye, A. (2005). Positive youth development, participation in community youth development programs, and community contributions of fifth-grade adolescents: Findings from the first wave of the 4-H study of positive youth development. Journal of Early Adolescence, 25(1), 17-71. doi:10.1177/0272431604272461

Lerner, J. V., Bowers, E., Minor, K., Boyd, M. J., Kiely Mueller, M., Schmid, K. L., ... Lerner, R. M. (2013). Positive youth development: Processes, philosophies, and programs. In R. M. Lerner, M. A. Easterbrooks, J. Mistry, \& I. B. Weiner (Eds.), Handbook of psychology: Developmental psychology ( $2^{\text {nd }}$ ed., Vol. 6, pp. 365-392). Hoboken, NJ: John Wiley \& Sons, Inc.

Meschke, L. L., Peter, C. R., \& Bartholomae, S. (2012). Developmentally appropriate practice to promote healthy adolescent development: Integrating research and practice. Child \& Youth Care Forum, 41(1), 89-108. doi: 0.1007/s10566-011-9153-7

Mincemoyer, C., \& Perkins, D. F. (2001). Making decisions in everyday life [Measurement instrument]. Retrieved from http://www.humanserviceresearch.com/youthlifeskillsevaluation/

Perkins, D. F., \& Borden, L. M. (2003). Key elements of community youth development programs. In F. A. Villarruel, D. F. Perkins, L. M. Borden, \& J. G. Keith (Eds.), Community youth development: Practice, policy, and research (pp. 327-340). Thousand Oaks, CA: Sage.

Perkins, D. F., Borden, L. M., Keith, J. G., Hoppe-Rooney, T., \& Villarruel, F. A. (2003). Community youth development: A partnership for creating a positive world. In F. A. Villarruel, D. F. Perkins, L. M. Borden, \& J. G. Keith (Eds.), Community youth development: Practice, policy, and research (pp. 1-23). Thousand Oaks, CA: Sage.

Rhodes, J. E. (2004). The critical ingredient: caring youth-staff relationships in after-school settings. New Directions for Youth Development, (101), 145-161. doi:10.1002/yd.75

Roth, J. L., \& Brooks-Gunn, J. (2016). Evaluating youth development programs: Progress and promise. Applied Developmental Science, 20(3), 188-202. doi: 10.1080/10888691.2015.1113879

Smith, E. P., Witherspoon, D. P., \& Wayne Osgood, D. (2017). Positive youth development among diverse racial-ethnic children: Quality afterschool contexts as developmental assets. Child Development, 88(4), 1063-1078. doi:10.1111/cdev.12870 
Journal of Youth Development | http://jyd.pitt.edu/ | Vol. 13 Issue 4 DOI 10.5195/jyd.2018.587

Youth Competencies and Program Quality

Taheri, S. a., \& Welsh, B. C. (2016). After-school programs for delinquency prevention: A systematic review and meta-analysis. Youth Violence and Juvenile Justice, 14(3), 272-290. doi: $10.1177 / 1541204014567542$

U.S. Department of Agriculture. (n.d.). Children, Youth and Families at Risk (CYFAR) | National Institute of Food and Agriculture. Retrieved June 30, 2017, from https://nifa.usda.gov/program/childrenyouth-and-families-risk-cyfar

U.S. Department of Agriculture, University of Minnesota, \& Penn State. (2016). 2016 CYFAR Annual Report. Retrieved from https://nifa.usda.gov/sites/default/files/resource/2016 -YFAR Annual Report-.pdf

University of Minnesota. (2017a). CYFAR approved common measures. Retrieved November 17, 2017, from https://cyfar.org/ilm_common_measures

University of Minnesota. (2017b). Frequently asked questions | CYFAR. Retrieved December 6, 2017, from https://cyfar.org/faqs

Walker, J. A., Gambone, M. A., \& Walker, K. C. (2011). Reflections on a century of youth development research and practice. Journal of Youth Development, 6(3), 7-19. doi:10.5195/jyd.2011.172

Yohalem, N., \& Wilson-Ahlstrom, A. (2010). Inside the black box: Assessing and improving quality in youth programs. American Journal of Community Psychology, 45(3), 350-357. doi:10.1007/s10464-010-9311-3

Zarrett, N., \& Bell, B. A. (2014). The effects of out-of-school time on changes in youth risk of obesity across the adolescent years. Journal of Adolescence, 371), 85-96.

doi:10.1016/j.adolescence.2013.11.001 